Research Article

\title{
Deformation and Mechanical Properties of a Constant-Friction-Force Energy-Absorbing Bolt
}

\author{
Tao Song $\mathbb{D})^{1,2}$ Tianbin Li $\mathbb{D}^{1,2}$ Lubo Meng, ${ }^{1,2}$ Chunchi Ma $\mathbb{D}^{1,2}$ Chaofei Li, ${ }^{1,2}$ \\ and Feng Peng ${ }^{1,2}$ \\ ${ }^{1}$ State Key Laboratory of Geohazard Prevention and Geoenvironment Protection, Chengdu University of Technology, \\ Chengdu 610059, China \\ ${ }^{2}$ College of Environment and Civil Engineering, Chengdu University of Technology, Chengdu 610059, China
}

Correspondence should be addressed to Tianbin Li; ltb@cdut.edu.cn

Received 11 June 2021; Revised 19 September 2021; Accepted 24 September 2021; Published 16 October 2021

Academic Editor: Quoc-Bao Bui

Copyright (c) 2021 Tao Song et al. This is an open access article distributed under the Creative Commons Attribution License, which permits unrestricted use, distribution, and reproduction in any medium, provided the original work is properly cited.

The conventional bolts used in surrounding rock tunnels with large deformation often fail. As a solution to this problem, we developed an extensible bolt with energy-absorbing and constant-friction-force (EACF) characteristics. The EACF bolt mainly comprises a damping device, a hollow threaded bolt, a tightening nut, and a face plate. To reveal its working mechanism, the bolt was tested in terms of its friction, displacement, and energy absorption through a modified tensile test device in a laboratory. The static pull-out test results showed that the axial force-displacement curve of the bolt can be mainly divided into three stages: a conical extrusion stage, an elongation stage, and an elastic failure stage. The EACF bolts exhibited stable energy absorption behaviors when subjected to static loading. The maximum constant friction force could be adjusted by increasing the size and diameter of the straight section of the damping block, and the maximum elongation could be adjusted by increasing the length of the damping cylinder. When the properties of the bolt materials are kept constant, increasing the diameter of the damping block can help achieve a high constant resistance. The proposed EACF bolt has reliable deformation and energy-absorption properties, which ensure its stability when employed in tunnels under the combined action of support and surrounding rocks.

\section{Introduction}

Rock bolts are employed in civil and underground engineering projects (e.g., tunneling excavation and roadway supports). With the increasing complexity of geological conditions, a surrounding rock is mainly characterized by large deformation [1], which can be divided into two cases. In the first case, the rock mass is soft. The self-stability of a soft rock roadway is poor, and soft rocks typically exhibit a creeping behavior, wherein the rock deformation increases with time. In the second case, after roadway excavation, the surrounding rock under a high in situ stress is mostly in the overload state and exhibits a large deformation [2]. In such cases, conventional bolts are easily damaged in advance under the excessive load, causing pull-out and fracture of the bolt [3]. The root causes of this problem are the low elongation and easy yielding of the bolt. Hence, it is necessary to improve the elongation and bearing capacity of bolt-support systems [4]. Under a high stress, with the deformation of the surrounding rock bolt quickly reaching or approaching its ultimate load, the deformation continues for a sufficient distance while maintaining a high load. Therefore, an ideal energy-absorbing or pressure-yielding bolt should have both sufficient strength and good deformation characteristics [5].

Existing large-deformation energy-absorbing bolts can be classified into two categories based on the working principle. In the first category, we have extensible and sliding extensible bolts with structural elements. Examples include rod extensible bolts, such as D bolts [6], J energy-releasing bolts [7], energy absorption bolts [8], and TCC yielding rock bolts [9]. The bolt structure or the elongation of the performance material is changed to provide anchor displacement; however, it is difficult to control the amount ofCE 
elongation. The D bolt is made of a round steel with a certain number of anchorage points at certain intervals; however, because the threaded part of the bolt is weak [10], the amount of deformation between adjacent anchorage units is small, and damage can be easily induced [11].

In the other category, we have sliding and extensible anchor bolts with structural elements, including cone bolts [12], Garford bolts [13], Roofex bolts [14], He-bolts [15], and AIEA-T bolts [16]. In these bolts, sliding elongation occurs mainly through a mechanical structure. However, this specific structure increases the number of processing steps required for the anchor, particularly in terms of material selection, and also increases the cost. A Garford bolt is made of round steel and has an anchor head and a threaded steel sleeve. Because of the large diameter of anchor rods, largediameter anchor holes are required, and the installation cost is high. He-bolts are prepared by incorporating a constantresistance device into the common anchor rod to achieve a constant resistance and pressure function, and the constantresistance value is typically in the range of $150-200 \mathrm{kN}$ in the test. However, the Ti sleeve tube is expensive [17].

Because anchor bolts have various drawbacks in terms of the constant friction force, maximum displacement, stability, and production cost, these energy-absorbing bolts cannot sufficiently adapt to the characteristics of large deformation of surrounding rocks under high stress conditions. Therefore, this study developed an extensible bolt with energy-absorbing and constant-friction-force (EACF) characteristics. In the rest of this paper, we introduce the structural composition and working mechanism of the proposed EACF bolt, report its mechanical characteristics analyzed by conducting static tensile experiments, and present the effects of damping block size on the constant resistance, tensile displacement, and energy absorption. EACF bolts are expected to provide a new and reliable means of support for the large deformation observed in tunnel surrounding rocks.

\section{Structure and Working Mechanism of EACF Bolt}

2.1. Structural Composition of EACF Bolt. The EACF bolt comprises a threaded hollow bolt, a damping device (including a damping cylinder, a damping block, and a damping tube), a sealing steel ring, a tightening nut, and a face plate (Figure 1). The outer diameter and thickness of the damping cylinder are 50 and $5 \mathrm{~mm}$, respectively. The outer diameter and thickness of the threaded hollow anchor bolt are 25 and $7 \mathrm{~mm}$, respectively. The damping block comprises straight and tapered sections and is connected to the threaded hollow bolt as a single unit by the tightening nut. The damping device can be located inside the anchor hole or outside. The EACF bolt described in this paper is equipped with a damping device at the end and a face plate and tightening nut at the front. The interaction between the components in the damping device not only generates a constant friction force to achieve energy absorption but also determines the constant-resistance displacement by changing the length of the damping cylinder. The strength of the damping tube is lower than that of the damping block; this helps prevent frictional failure of the block. Therefore, the constant friction force provided by the EACF bolts can be adjusted to meet the different requirements of practical engineering applications, making them more applicable.

\subsection{EACF Bolt-Surrounding Rock Interaction. In the EACF} bolt, the sliding of the damping block in the damping device helps achieve the yield. During the sliding process, the mutual friction between the damping block, damping cylinder, and damping tube provides a constant load-bearing capacity; after the set reserved deformation is released, the EACF bolt is transformed into a normal bolt, at which time the load-bearing capacity will be the same as that of a normal bolt. To achieve an ideal operation of the EACF bolt and ensure that it starts to slip at the nodes before yielding, the following requirements should be met: the maximum static friction of the bolt should be less than the yield strength of the normal bolt.

Since the drill hole of a conventional bolt has an aperture range of 28-32 $\mathrm{mm}$, installing the damping device inside the hole will expand the hole diameter, which requires more procedures, special machine, and more time. For example, an NPR anchor cable requires a special reaming drill to enlarge the drilled hole to install a constant-resistance device [18]. Therefore, we installed the damping device of the EACF bolt outside the hole. The installation of the EACF bolt was the same as that of the conventional rock bolt.

Figure 2 shows the working process. The EACF bolt is driven into the surrounding rock area, and the fixed length of the hollow threaded bolt is anchored by grouting. The bolt can reserve a certain length of the displacement through the damping device, as shown in Figure 2(a). When the surrounding rock deformation is large at the free length, the bolt will be subjected to the pulling force of the tunnel's critical surface. The damping block and anchor will slide outward along the inner side of the damping cylinder. When the straight section of the damping block enters the inner part of the damping cylinder, the conical section of the damping block continuously compresses the damping tube, and the damping tube will be squeezed into the thin plate, thereby generating a frictional force. At the same time, friction is generated between the straight section of the damping block and the inner wall of the damping cylinder. The interaction between the two generates a constant friction force in the damping cylinder. When the reserved deformation is released, the damping block and the sealing steel ring are in contact with each other, and the axial force is borne by the threaded hollow bolt, as shown in Figure 2(b).

Figure 3 illustrates the interaction relationship between the EACF bolt support and the surrounding rock. Curve 1 is the characteristic curve of the surrounding rock of the tunnel under unsupported conditions. Curve 2 is the normal bolt support with the same support stiffness and material. The characteristic curve of the support of the EACF bolt (Curve 3) has an additional yielding process, i.e., the displacement of $\Delta u$. The intersection points "a" and "b" in Curve 1 and Curves 2 and 3 are the equilibrium points of the ordinary 


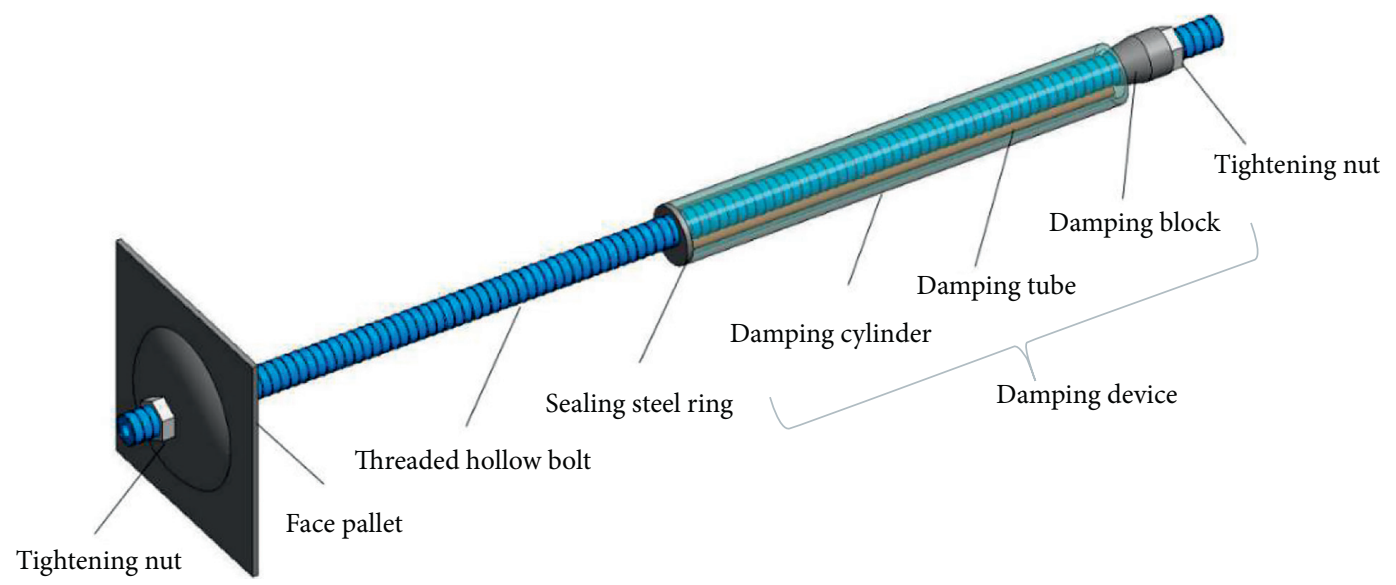

FIgURE 1: Schematic of EACF bolt.

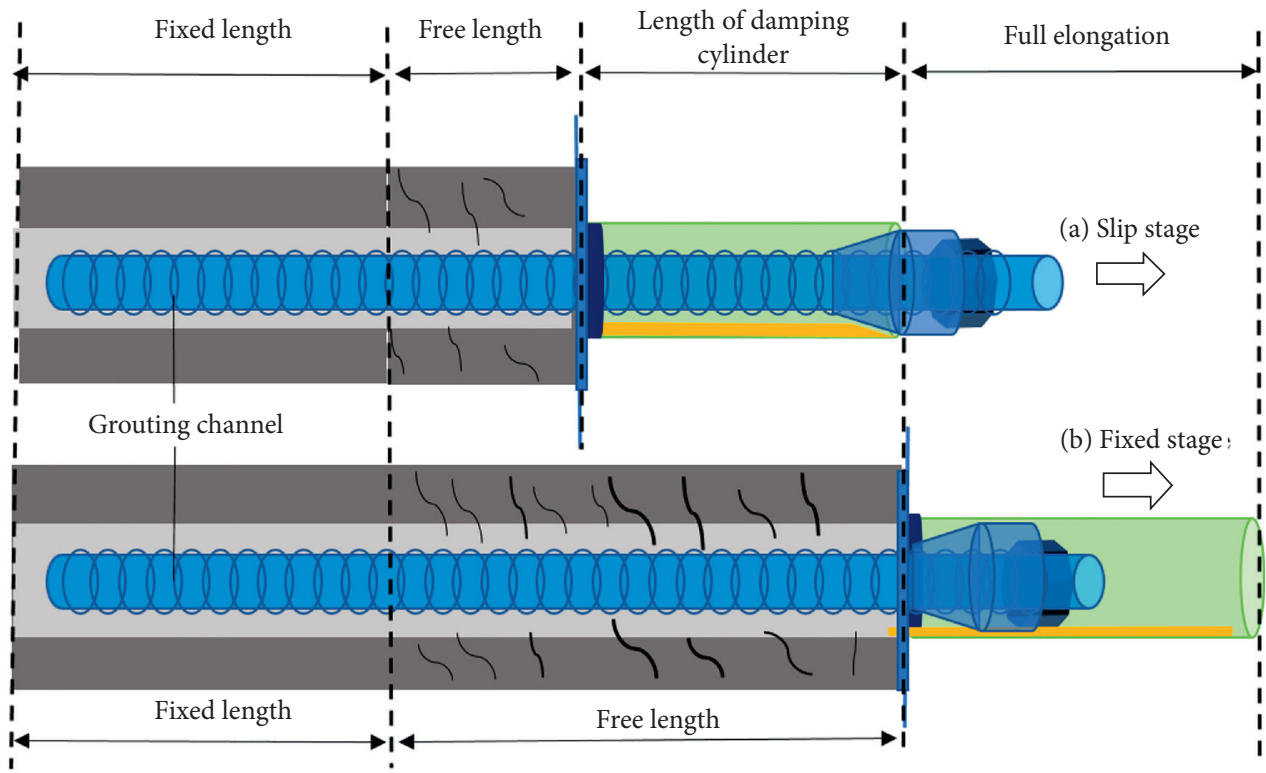

Figure 2: Working process of EACF bolt.

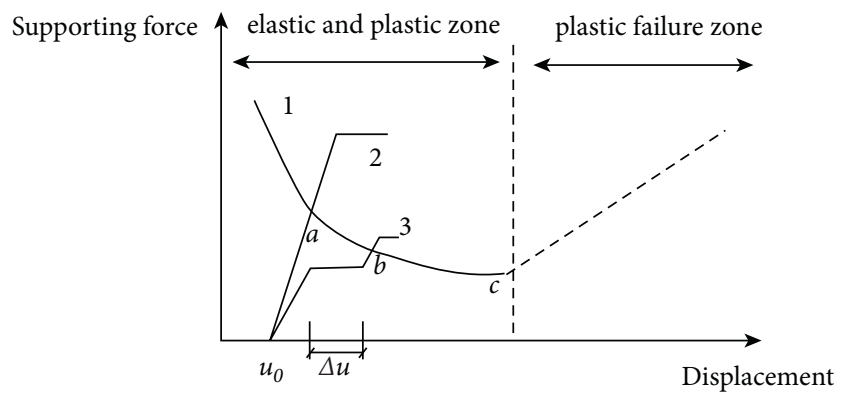

Figure 3: Convergence-confinement curves for different supporting concepts.

bolt and EACF bolt support, and they are both in the elastic stage of support, and the support system has good safety. Point $c$ is the stable equilibrium point of the surrounding rock. When the supporting structure cannot work normally in the loosening failure zone, the action point of the supporting structure should be near the left side of point $c$. The normal bolt (Curve 2) can reduce the deformation of the roadway surrounding rock by increasing the support stiffness and the support resistance; however, because of the high position of the balance point between the surrounding rock and the anchor bolt support, the support structure will be in a high internal force state, the normal bolt support structure will be under a higher stress, and the support resistance corresponding to point "a" will be much greater than the support resistance at point "b."

Therefore, the EACF bolt exhibits constant resistance and yield, whereby a certain amount of constant-resistance displacement is released to adapt to the deformation of the surrounding rock. It can also ensure the stability of the surrounding rock with a relatively low working resistance, effectively prevent the bolt from entering the yielding stage prematurely, and ensure that the bolt will not be destroyed 
prematurely during the support duration, which not only improves the support life but also contributes to the longterm stability of the rock mass. Hence, the EACF bolt represents a reasonable solution for large-deformation support of soft rocks.

\section{Static Pull-Out Test Analysis}

3.1. Test Plan and Equipment. To study the energy absorption performance and extensibility of the EACF bolt, the constant friction force of the bolt was analyzed by varying the diameter and length of the linear section of the damping block with the same material properties of the damping device.

Nine different combinations of dimensions with diameters of $38,38.5$, and $38.7 \mathrm{~mm}$ and straight segment lengths of 20,25 , and $30 \mathrm{~mm}$ were prepared, denoted by BG-1 to BG9. The test equipment was improved to meet the test requirements with a maximum load of $500 \mathrm{kN}$, a maximum displacement of $150 \mathrm{~mm}$, a loading rate of 0.1 to $20 \mathrm{kN} / \mathrm{min}$, a displacement rate of 0.5 to $100 \mathrm{~mm} / \mathrm{min}$, a damping cylinder length of $100 \mathrm{~mm}$, and a tensile displacement of $100 \mathrm{~mm}$. The constant speed set in the tensile test was $10 \mathrm{kN} /$ min.

Considering the special characteristics of the damping device, the damping cylinder and the damping tube were made of fixed size and fixed material to ensure that they exhibited good strength and ductility. The outer diameter/ thickness of the damping cylinder, damping tube, and anchor bolt were $50 / 5,12 / 2$, and $25 / 7 \mathrm{~mm}$, respectively. The modulus of elasticity of the damping cylinder material was $5000 \mathrm{MPa}$. The high load-bearing damping block was made of 20\# steel, which is much harder than the damping cylinder. The modulus of elasticity and Poisson's ratio of the 20\# steel were $200 \mathrm{GPa}$ and 0.3 , respectively. The hollow threaded bolt was made of Q345 steel. The yield strength and ultimate strength were 360 and $510 \mathrm{MPa}$, respectively.

Test data were obtained through a modified tensile test system designed for the EACF bolt (Figure 4). This specialized monitoring system was welded to both sides of the monitoring system to help transmit and record the pulling forces. The EACF bolt was passed through the hollow ring to provide an opposite reaction force during the test, and a linear displacement transducer was fixed to the test equipment to monitor the tensile length of the bolt (Figure 5). In addition, the top steel bar of the monitoring system and the bottom of the bolt were fixed and adjusted using the tensile test equipment; this ensured that the monitoring system and the EACF bolt were in the same plane. However, the steel ring at the bottom of the damping cylinder was not considered in the test. Therefore, the test was stopped when the bolt was completely pulled out of the damping cylinder.

3.2. Experimental Procedure. As shown in Figure 6, the pullout tests on BG-1, BG-2, and BG-3 indicate that the test process can be divided into two stages: an axial force rise stage and an axial force balance stage. During the 0-60 mm

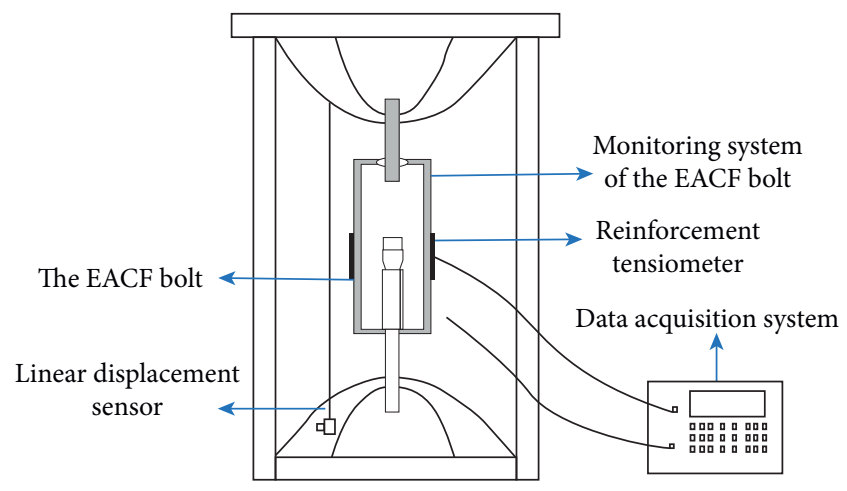

Figure 4: Schematic of a modified tensile test device.

stroke, the resistance gradually increases with some fluctuations, and when the damping block completely slides into the damping cylinder, the tension value stabilizes. The constant-friction-force strokes of BG-1, BG-2, and BG-31 are $39.4,39.2$, and $39.6 \mathrm{~mm}$, respectively. The average constant resistances are 60,63 , and $67 \mathrm{kN}$.

As shown in Figure 7, the pull-out tests of BG-4, BG-5, and BG-6 indicate that the test process can be divided into a resistance rise stage and a resistance balance stage. During the $0-60 \mathrm{~mm}$ stroke, the resistance gradually increases with some fluctuations, and when the damping block completely slides into the damping cylinder, the tension value stabilizes. The constant-resistance strokes of BG-4, BG-5, and BG-6 are $39.7,39.7$, and $39.8 \mathrm{~mm}$, respectively. The average constant resistances are 72,75 , and $78 \mathrm{kN}$.

As shown in Figure 8, from the pull-out tests on BG-7, BG-8, and BG-9, the conditions of the previous specimens are similar during the test. The constant-resistance strokes of BG-7, BG-8, and BG-9 are $39.6,39.8$, and $39.5 \mathrm{~mm}$, respectively. The average constant resistances are 80,83 , and $87 \mathrm{kN}$.

In summary, as listed in Table 1, different damping block sizes have a certain effect on the constant resistance of the EACF bolt. The test showed that the static friction is the main force at the beginning of the test, and there is no relative displacement between the damping block, the damping tube, and the damping cylinder. With the continuation of the test process, the friction force and displacement increase. When the damping block completely enters the damping cylinder, the EACF bolt reaches the maximum friction force, which gradually stabilizes with the fluctuation, which is a constant friction force until the end of the reserved displacement.

3.3. Mechanical Analysis of EACF Bolt. As shown in the figure, the mechanical properties of the normal and EACF bolts are evidently different. The deformation damage stage of the ordinary bolt is the $O-A^{\prime}-B^{\prime}-C^{\prime}-D^{\prime}$ stage, whereas that of the EACF bolt is the O-A-B-C-D stage. The main difference between the normal and EACF bolts is the yieldingenergy absorbing platform of $A B$; therefore, this study mainly focuses on the elongation stage of the constant friction force. Based on the mechanical curve of the tensile 


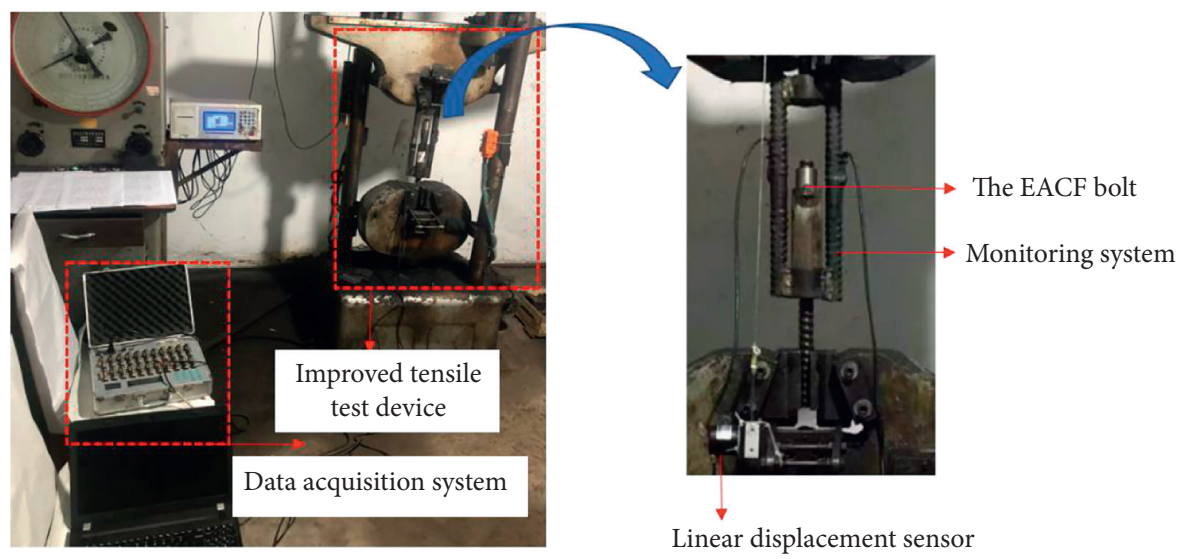

Figure 5: Monitoring device of the EACF bolt.

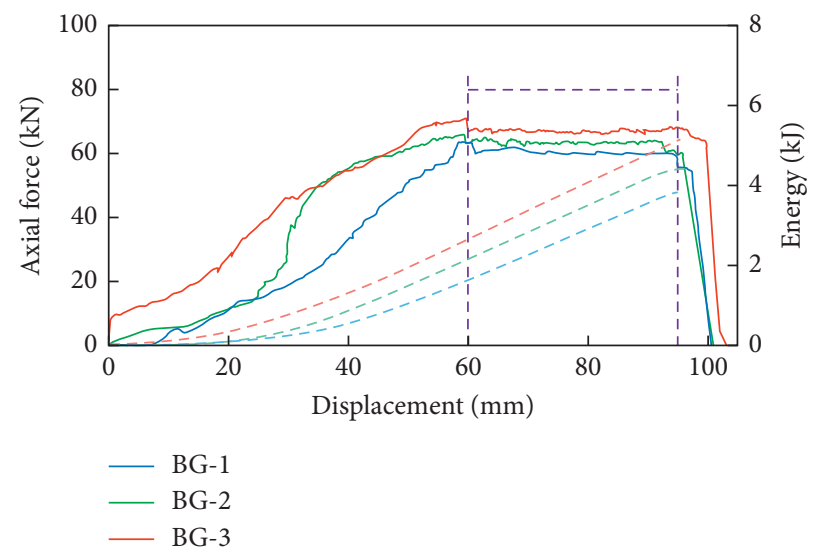

FIGURE 6: Energy and displacement diagrams of BG-1, BG-2, and BG-3.

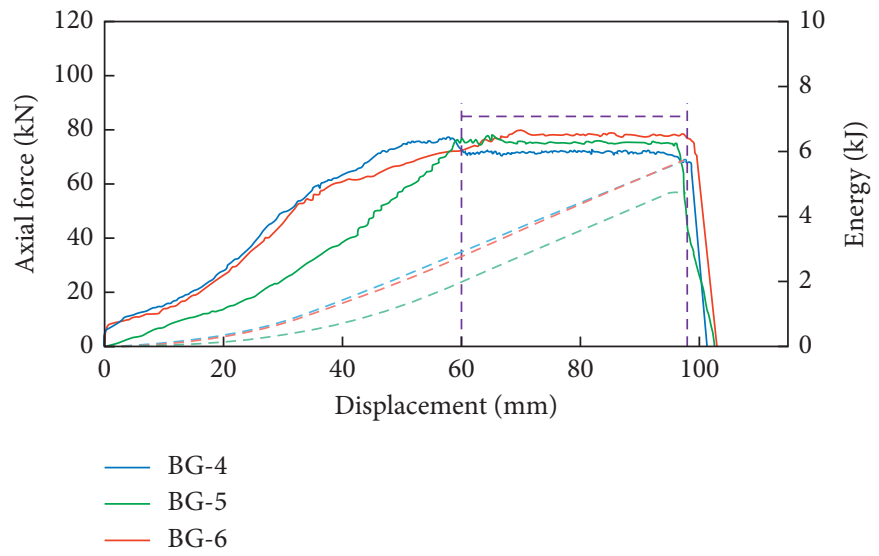

FIGURE 7: Energy and displacement diagrams of BG-4, BG-5, and BG-6.

test, the mechanism of the EACF bolt can be analyzed. The stress process of the EACF bolt includes three stages: a conical extrusion stage, an elongation stage of constant resistance, and an elastoplastic failure stage.

The conical extrusion stage corresponds to the OA stage shown in Figure 9. In the initial stage, there is a relative displacement between the damping block, the damping tube, and the damping cylinder. When the damping block squeezes the damping tube and damping cylinder, the tension increases linearly. Over time, the friction and displacement increase rapidly. However, the ordinary bolt is mainly in the elastoplastic stage in the $\mathrm{OA}^{\prime}$ stage. As the pressure increases, the deformation of the bolt is not evident, and it shows a linear increase. Here, the curves of the two bolts have the same characteristics. 


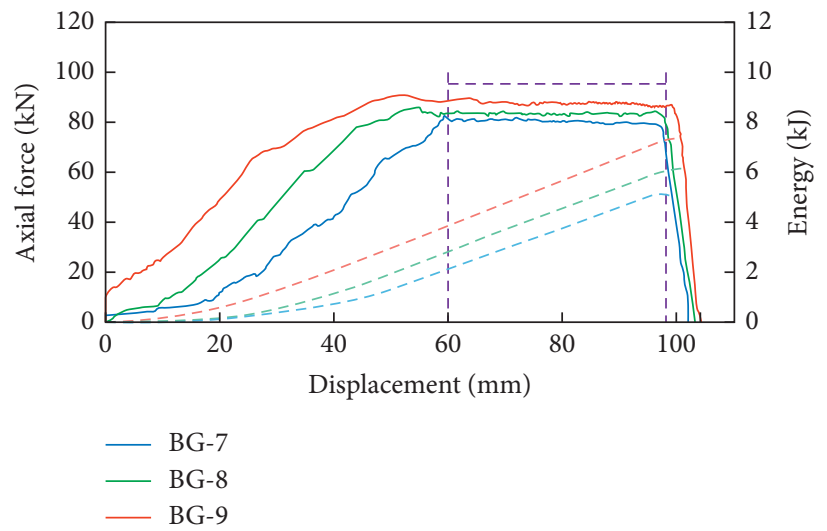

FIgURE 8: Axial force, energy, and displacement diagrams of BG-7, BG-8, and BG-9.

TABLE 1: Tensile test results of the EACF bolt.

\begin{tabular}{|c|c|c|c|c|c|}
\hline $\begin{array}{l}\text { Types of } \\
\text { EACF bolts }\end{array}$ & $\begin{array}{c}\text { Diameter of the straight section } \\
\text { of the damping } \\
\text { block }(\mathrm{mm})\end{array}$ & $\begin{array}{l}\text { Straight line length of the } \\
\text { damping block } \\
(\mathrm{mm})\end{array}$ & $\begin{array}{c}\text { Average } \\
\text { constant-friction } \\
\text { force }(\mathrm{kN})\end{array}$ & $\begin{array}{c}\text { Constant } \\
\text { displacement }(\mathrm{mm})\end{array}$ & $\begin{array}{l}\text { Absorbed } \\
\text { energy }(J)\end{array}$ \\
\hline BG-1 & 38 & 20 & 60 & 39.4 & 3806 \\
\hline BG-2 & 38 & 25 & 63 & 39.2 & 4407 \\
\hline BG-3 & 38 & 30 & 67 & 39.6 & 5215 \\
\hline BG-4 & 38.5 & 20 & 72 & 39.7 & 4687 \\
\hline BG-5 & 38.5 & 25 & 75 & 39.7 & 5064 \\
\hline BG-6 & 38.5 & 30 & 78 & 39.8 & 5746 \\
\hline BG-7 & 38.7 & 20 & 80 & 39.6 & 5116 \\
\hline BG-8 & 38.7 & 25 & 83 & 39.8 & 6097 \\
\hline BG-9 & 38.7 & 30 & 87 & 39.5 & 7340 \\
\hline
\end{tabular}

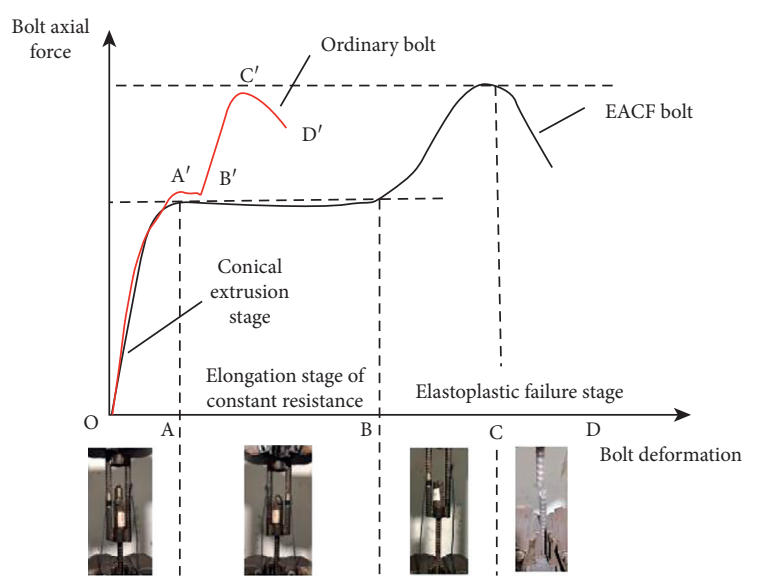

FIGURE 9: Mechanical property curves of EACF and normal bolts.

The elongation stage of the constant resistance corresponds to the $\mathrm{AB}$ stage shown in Figure 9. At this stage, as the straight part of the damping block completely enters the damping cylinder, the EACF bolt produces a constant friction force. This stage produces a platform. Compared with the $\mathrm{A}^{\prime} \mathrm{B}^{\prime}$ stage of the normal bolt, this stage is a controllable elongation displacement, and the proposed bolt evidently outperforms the normal bolt. The reason for this stage is that the constant friction force produced by the damping device is lower than the yield load of the bolt itself, which improves the deformation performance of the support system. Moreover, in terms of the energy absorption, the damping device of the EACF bolt absorbs most of the energy generated by tension and displacement, which is equivalent to absorbing the energy of the surrounding rock deformation. Therefore, the constant friction force and displacement are key factors that reflect the mechanical properties and energy absorption efficiency of the EACF bolt.

The elastoplastic failure stage corresponds to the BCD stage shown in Figure 9. When the damping block is fixed by the steel ring at the bottom of the damping cylinder, it no longer slides. The EACF bolt is now transformed into a normal bolt, and as the axial force of the bolt further increases, the bolt body reaches the yielding stage until the bolt breaks. This stage is similar to the $\mathrm{B}^{\prime} \mathrm{C}^{\prime} \mathrm{D}^{\prime}$ stage of the ordinary bolt.

\section{Discussion}

4.1. Effect of Damping Block Size on Constant Resistance. When the diameter of the linear section of the damping block remains constant, the constant friction force increases with the increase in the linear section length of the damping block, from 6 to $8 \mathrm{kN}$. Compared with the initial constant friction force, its increase is $8 \%$ to $10 \%$. As shown in Figure 10 , when the straight section length of the damping block 


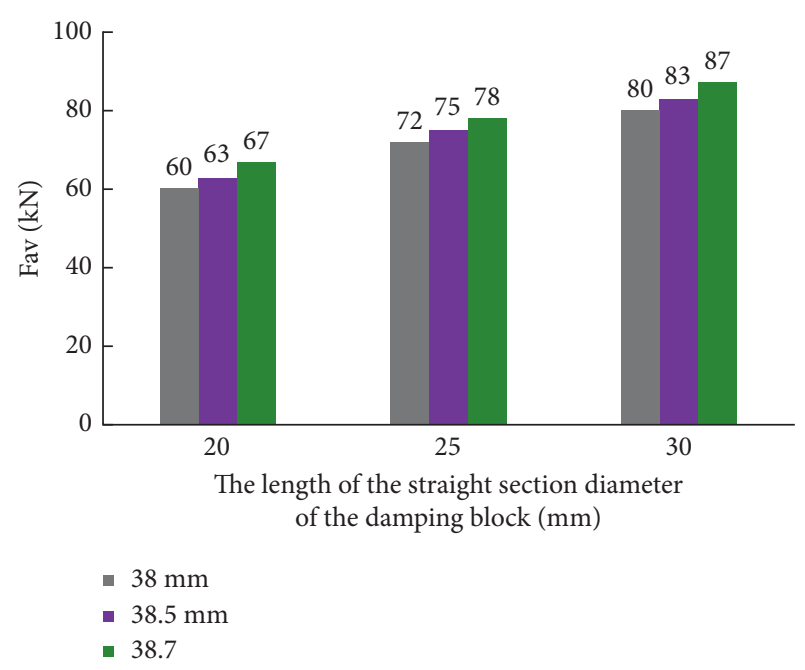

Figure 10: Effect of damping block size on energy-absorbing and constant-friction-force bolt.

remains constant, increasing the diameter of the damping block can help significantly increase the constant friction force. The increase is within $12-20 \mathrm{kN}$. Compared with the initial constant friction force, the maximum increase is $30 \%-$ $33 \%$. Therefore, when the size of the damping device is constant, increasing the diameter of the damping block can produce a more evident constant friction force.

4.2. Effect of Damping Block Size on Constant Tensile Displacement. The damping block size has little effect on the constant tensile displacement. As shown in Figures 6-8, the axial force increases rapidly to a peak at a displacement of approximately $60 \mathrm{~mm}$, i.e., the damping block completely enters the damping cylinder, indicating that the bolt can resist the deformation of the rock in a short extension range under static loading. Since the dimension of the conical section in the damping block is constant, the constant tensile displacement is mainly controlled by the length of the damping cylinder. More specifically, it is determined by the length of the damping cylinder minus the length of the damping block; therefore, the effect of constant tensile displacement is not significant in the stretching process. In soft rocks, the support length should be calculated to mitigate the hazard of large tunnel deformation through energy absorption.

\subsection{Energy Absorption Capacity of EACF Bolt under Different Damping Block Sizes. The EACF bolt has a good energy absorption capacity. The energy absorption capacity is the area under the axial force-displacement curve based on the static tensile test. Therefore, the total energy absorption depends on the level of the bearing capacity and displace- ment. The length of the damping cylinder is the same as that of the tensile displacement of the EACF bolt. When the length of the damping cylinder is increased, the energy absorbed by the EACF bolt increases.}

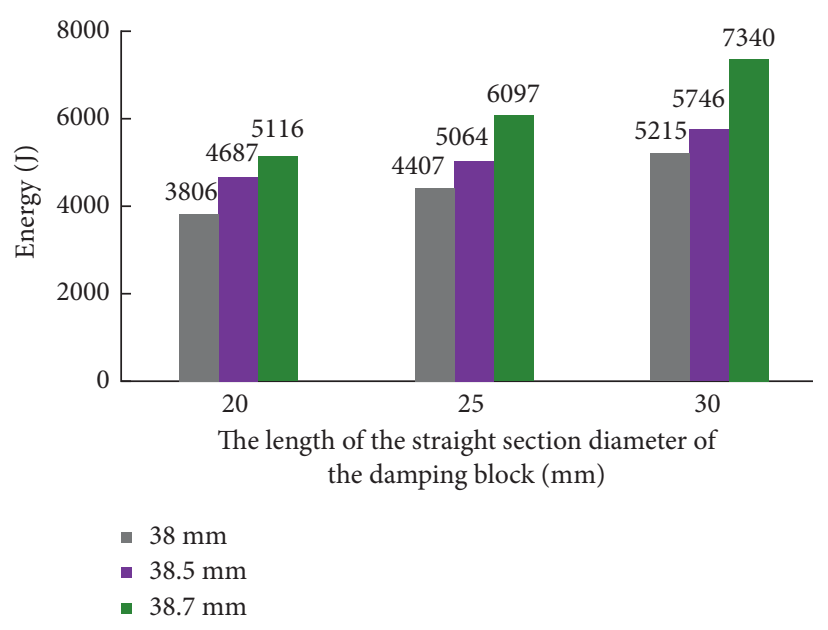

FIGURE 11: Effect of constant straight section length of the damping block on the energy-absorbing and constant-friction-force bolt.

From Figure 11, we find that the energy absorption capacity increases when increasing the diameter of the straight section of the damping block with the length of the straight section of the damping block being constant, and the range of increase is $34 \%-42 \%$ compared with the initial increase. When the diameter of the straight section of the damping block remains constant, the energy absorption capacity increases when increasing the straight section length of the block, with a range of $22 \%-39 \%$ compared with the initial increase. Therefore, the energy absorption increases with the increase in the damping block size; however, the increase in the energy absorbed by the EACF bolt is more evident with the increase in the damping block diameter.

The static load tensile test shows that the EACF bolt has the characteristics of constant-resistance displacement and constant resistance. The maximum constant force of $60-87 \mathrm{kN}$ reported in this paper meets the application requirements of highway tunnels through field investigation and literature research; the maximum constant force is generally in the range of $40-60 \mathrm{kN}[19,20]$. Compared with the installation of a damping device in the borehole, installing the damping device outside the borehole could help optimize the construction process in practical applications. Hence, the EACF bolt has certain application value, and we will further study its practical applications.

\section{Conclusions}

(1) We developed an extensible bolt with energy-absorbing and constant-friction-force characteristics, with functions such as constant friction force, variable displacement, and energy absorption. The constant support resistance is provided through the squeezing and sliding of the damping cylinder, damping block, and damping tube. The adjustable constant friction force ranges from $60 \mathrm{kN}$ to $87 \mathrm{kN}$, and the maximum extensible displacement is determined by the damping cylinder. Through static pull-out tests, we found that by adjusting the length of the damping device, the tensile displacement of 
the EACF bolt could be varied, the deformation energy of the surrounding rock due to the high ground stress could be absorbed, and the large deformation of the surrounding rock could be effectively supported. The dynamic performance for hard rocks will be investigated in the future.

(2) The tensile test results showed that increasing the diameter and length of the straight section of the damping block can help increase the constant friction force and energy absorption under the condition that the material performance of the damping device remains unchanged. When the diameter of the damping block is increased, the maximum increase range of the constant resistance is $30 \%-33 \%$; the range of increase in the energy absorption capacity is $22 \%-39 \%$ compared with the initial increase. Therefore, increasing the diameter of the damping block can help produce a more evident supporting effect.

(3) The experimental analysis showed that the elongation stage of the EACF bolt is evidently different from that of the normal bolt. The mechanical properties of the EACF bolt are mainly reflected in three stages: a conical extrusion stage, an elongation stage of the constant friction force, and an elastoplastic failure stage. The development of EACF bolts can release the internal energy of the surrounding rock, can effectively maintain its stability, and has a good reference value for the prevention and control of large deformation of tunnels.

\section{Data Availability}

The data used to support the findings of this study are available from the corresponding author upon request.

\section{Conflicts of Interest}

The authors declare that they have no conflicts of interest.

\section{Acknowledgments}

This study was supported by the National Natural Science Foundation of China (nos. U19A20111 and 41772329), the Research Fund of the State Key Laboratory of Geohazard Prevention and Geoenvironment Protection (nos. SKLGP2018Z009 and SKLGP2018Z016), and the Sichuan Science and Technology Planning Project (no. 2019YJ0538).

\section{References}

[1] K. Skrzypkowski, W. Korzeniowski, K. Zagórski, and A Zagórska, "Flexibility and load-bearing capacity of roof bolting as functions of mounting depth and hole diameter," Energies, vol. 12, no. 19, p. 3754, 2019.

[2] Z. Chen, C. He, G. Xu, G. Ma, and W. Yang, "Supporting mechanism and mechanical behavior of a double primary support method for tunnels in broken phyllite under high geo-stress: a case study," Bulletin of Engineering Geology and the Environment, vol. 78, no. 7, pp. 5253-5267, 2019.
[3] H. Kang, Y. Wu, F. Gao et al., "Mechanical performances and stress states of rock bolts under varying loading conditions," Tunnelling and Underground Space Technology, vol. 52, no. 2, pp. 138-146, 2016.

[4] C. C. Li, "Principles of rockbolting design," Journal of Rock Mechanics and Geotechnical Engineering, vol. 9, no. 3, pp. 396-414, 2017.

[5] M. Ghorbani, K. Shahriar, M. Sharifzadeh, and R. Masoudi, “A critical review on the developments of rock support systems in high stress ground conditions," International Journal of Mining Science and Technology, vol. 30, no. 5, pp. 557-572, 2020.

[6] C. Li, "A new energy-absorbing bolt for rock support in high stress rock masses," International Journal of Rock Mechanics and Mining Sciences, vol. 47, pp. 396-404, 2010.

[7] X. D. Zhao, Q. K. Zhu, J. A. Niu, X. Yang, S. Zhang, and Y. Chen, "Mechanical mechanism analyses and dynamic impact experimental tests of a kind of novel J energy-releasing bolts," Chinese Journal of Rock Mechanics and Engineering, vol. 39, pp. 13-21, 2020.

[8] A. W. Wang, Y. S. Pan, B. Y. Zhao, and J. Sheng, "Static and dynamic mechanical properties of energy absorption bolts (cable) and field tests," Chinese Journal of Geotechnical Engineering, vol. 39, no. 7, pp. 1292-1301, 2017.

[9] X. Wu, Y. Jiang, G. Wang, B. Gong, Z. Guan, and T. Deng, "Performance of a new yielding rock bolt under pull and shear loading conditions," Rock Mechanics and Rock Engineering, vol. 52, no. 9, pp. 3401-3412, 2019.

[10] B. Zhao, J. Li, A. Wang, and H. Xiang, "Theoretical and numerical analysis of a new energy-absorbing rock bolt with controllable constant resistance and large displacement," Tunnelling and Underground Space Technology, vol. 106, 2020.

[11] X. Z. Wu, G. Wang, Y. J. Jiang, B. Gong, and B. Li, "Mechanism of CTC-yield bolts and its experimental research," Chinese Journal of Geotechnical Engineering, vol. 37, no. 1, pp. 139-147, 2015.

[12] A. J. Jager, "Two new support units for the control of rockburst damage," in Proceedings of the International Symposium Rock Support in Mining and Underground Construction, pp. 621-631, Rotterdam: Balkema, 1992.

[13] R. Varden, R. Lachenicht, J. Player, and A. Thompson, "Development and implementation of the Garford dynamic bolt at the kanowna belle mine," in Proceedings of the 10th Underground Operators' Conference, pp. 14-16, Launceston, Australia, 2008.

[14] E. Neugebauer, "Ready for roofex-a new way to tackle safety in underground operations," Min Construct, vol. 3, pp. 12-13, 2008.

[15] M. He, W. Gong, J. Wang et al., "Development of a novel energy-absorbing bolt with extraordinarily large elongation and constant resistance," International Journal of Rock Mechanics and Mining Sciences, vol. 67, pp. 29-42, 2014.

[16] L. Dai, Y. Pan, A. Wang, Y. Xiao, and X. Ma, "Experimental study on the self-protection performance of anchor bolts with energy-absorbing tails," Rock Mechanics and Rock Engineering, vol. 53, no. 5, pp. 2249-2263, 2020.

[17] Y. Hao, Y. Wu, P. G. Ranjith, and K. Zhang, "A novel energyabsorbing rock bolt with high constant working resistance and long elongation: principle and static pull-out test," Construction and Building Materials, vol. 243, 2020.

[18] X. M. Sun, B. Zhang, G. Li, T. Zhigang, and Z. Chengwei, "Application of constant resistance and large deformation anchor cable in soft rock highway tunnel," Advances in Civil Engineering, vol. 2019, Article ID 4347302, 2019.

[19] B. Zhang, Z. Q. Zhang, B. Wang, and L. Zhou, "Experimental study of application of yielding bolt to large deformation tunnel," Rock And Soil Mechanics, vol. 37, no. 7, pp. 2047-2055, 2016. 
[20] L. X. Kong, K. Gu, and S. Zhang, "Experimental study of application of yielding bolt to large deformation tunnel," Chinese Journal of Underground Space and Engineering, vol. 16, no. S01, pp. 55-58, 2020. 